\title{
结构化学课程教学中融入思政元素的探索
}

王渭娜，刘峰毅，王文亮*

陕西师范大学化学化工学院, 西安 710119

摘要: 在高等学校专业课程教学中融入思政教育教学的理念, 是以 “立德树人” 为教育根本任务的基本要求。结合 结构化学课程特点和教学内容, 以 “培养学生的哲学观和科学观、培养学生民族自豪感和自信心” 的目标为切入 点, 提出结构化学教学中思政元素的融入策略, 发挥结构化学课程的 “育德功能”, 实现知识传授和价值引领的 有机统一。

关键词: 结构化学; 课程思政; 策略

中图分类号: G64; O6

\section{Exploration of Course Ideology and Politics in Structural Chemistry Teaching}

\section{Weina Wang, Fengyi Liu, Wenliang Wang *}

School of Chemistry and Chemical Engineering, Shaanxi Normal University, Xi'an 710119, China.

\begin{abstract}
The integration of professional courses and ideological and political education is the fundamental task of moral education in colleges and universities. In this study, based on the character and teaching objectives of structural chemistry, possible methods for ideological and political education in the course are explored for cultivating students' philosophy and science, national pride and self-confidence in order to realize the organic unity of knowledge imparting and value leading.
\end{abstract}

Key Words: Structural chemistry; Course ideology and politics; Strategy

\section{1 引言}

2016年12月, 习近平总书记在全国高校思想政治工作会议上指出 “要坚持把立德树人作为中心 环节, 把思想政治工作贯穿教育教学全过程, 实现全程育人、全方位育人” ${ }^{[1]}$ 。充分发挥课堂育人主 渠道作用, 构建思政课与其他课程协同育人的工作机制, 推动 “思政课程” 向 “课程思政” 的立体 化育人转型, 正在成为高等学校课程建设与课程改革的任务, 目前本科教学新体系中已经全面开展 “课程思政”下的课程重构研究 ${ }^{[2-5]}$ 。专业课教师在开展课程思政工作中具有得天独厚的优势, 可以 更有针对性和有实效地在潜移默化中引领大学生解决好世界观、人生观、价值观这个 “总开关” 问 题。2021年3月6日习近平总书记在看望参加政协会议的医药卫生界、教育界委员时指出: “把立德树 人融入思想道德教育、文化知识教育、社会实践教育各环节, 贯穿基础教育、职业教育、高等教育 各领域, 体现到学科体系、教学体系、教材体系、管理体系建设各方面, 培根铸魂、启智润心。” 课

收稿: 2021-04-16; 录用: 2021-06-21; 网络发表: 2021-07-01 
程思政是高等学校完善全员全程全方位育人的重要抓手, 它以科学有效的教育教学原则为指导, 在 大学专业课(非思政课)教学中, 融入思想观念、政治观点、道德规范等思想政治教育, 提升育人效 果。结构化学是化学相关专业的基础理论课程, 该课程以量子力学为理论基础, 从微观角度研究原 子、分子及晶体的结构与性质, 培养学生分析和解决化学问题的能力等。从结构化学课程的能力目 标来看, 该课程是思政教育的一个合适载体, 加强思政元素的融入, 有助于培养学生的科学素养、 思维方式。如何在结构化学中贯穿思政教育, 实现结构化学课程的协同育人功能, 需要教师细致而 深入的研究和实践, 对课程思政进行合理设计和正确实施, 从而达到同时提升学生专业素养和德育 素养。

\section{2 结构化学开展课程思政的困难}

结构化学课程是从事化学相关研究工作的学者不可缺少的基本知识和基本训练。通过该课程的 学习, 使学生学会用微观角度分析化学问题, 理解 “结构决定性质, 性质反映结构” 的普遍规律 ${ }^{[6,7]}$, 为进一步学习和研究打下必要的基础。相对其他化学类课程而言, 结构化学课程有其自身的特点, 在开展课程思政建设方面存在一些困难。结构化学以微观结构为研究对象, 课程内容理论性强, 逻 辑性强, 抽象难懂。在学习过程中, 要求学生既要有与化学相关的基础知识, 又要有一定的数理基 础知识, 同时还需具备较好的空间想象力、严密的逻辑思维、抽象思维以及演绎推理的能力。这些 特点给课程的教与学都带来很大困难。因此, 该课程中融入思政元素更是困难, 如果采取的方式方 法不当，就容易导致生搬硬套、出现两张皮现象。

结构化学开展课程思政也有其优势, 主要表现在: 结构化学是研究物质的结构及其变化规律的 科学, 课程富含哲学观、科学观(科学精神、科学思想、科学方法)等思政元素, 教学内容贯穿辩证唯 物主义思想, 对培养未来科学工作者有着重要的意义。作为化学专业本科阶段的重要基础理论课程, 通过结构化学课程学习, 对完善学生的化学专业知识结构, 掌握化学学科的基础理论, 更新学生对 化学专业认知的观念, 培养学生抽象思维能力、创新精神等都将起到重要作用。

\section{3 挖掘结构化学课程思政策略}

理科专业课程实施 “课程思政” 并不是简单机械地在授课过程中进行思想政治教育, 而是要结 合课程内容与特点, 引入适当的思政元素, 赋予普通理科课程更多内涵, 提升学生的哲学观与科学 观。目前关于结构化学课程教学改革的论文多数侧重于宏观方面, 而较为具体的课程思政案例教学 内容鲜有报道。本文就我们在结构化学课程建设中的课程思政元素挖掘、案例设计方面的探索与实 践做一些介绍和总结。

\section{1 从结构化学教学内容出发挖掘思政元素}

课堂教学中对科学方法的剖析有助于形成批判性思维, 这一点在现代社会中很重要。结构化学 课程中的认识论、方法论符合辩证唯物主义, 从马克思主义哲学思想出发, 挖掘结构化学课程中 “对 立与统一” “现象与本质” “具体与抽象” 等辩证关系, 使学生懂得, 学好辩证法是深入理解结构 化学理论的关键; 挖掘结构化学课程中蕴含的发展观、实践观、认识论, 培养学生的科学观。

\section{案例一：晶体结构的点阵理论(具体与抽象、个性与共性、复杂与简单)}

晶体结构是结构化学中的重点内容之一, 其突出特点是抽象。抽象思维是人们在认识活动中运 用概念、判断、推理等思维形式, 对客观现实进行间接的、概括的反映的过程, 属于理性认识阶段。 它是在对事物的本质属性进行分析、综合、比较的基础上, 抽取出事物的本质属性, 擞开其非本质 属性, 使认识从感性的具体进入抽象的规定, 形成概念。点阵结构理论的创立是应用具体-抽象一具 体的科学抽象方法的典范。实际晶体结构千差万别、形式多样, 但若将结构中等同部分抽取为几何 上的点(点阵)来研究, 只能分为 7 个晶系 -14 种空间格子 -32 个点群 -230 个空间群, 此为晶体结构的共 性; 若将结构基元(几何点代表的具体内容)放置在点阵处, 就由共性还原到个性。共性即普遍性, 个 
性即特殊性, 两者密切联系, 不可分割, 是辩证统一的关系。共性寓于个性之中, 并通过个性表现 出来, 没有个性就没有共性; 个性也离不开共性。世界上的事物无论如何特殊, 它总是和同类事物 中的其他事物有共同之处, 总要服从于这类事物的一般规律, 不包含普遍性的特殊性是没有的, 即 特殊性也离不开普遍性。这是哲学中关于 “个性与共性” “具体与抽象” 辨证关系在化学中的体现。 这样以鲜活的知识作为载体, 学习冷情的哲学思想, 正是思政元素无形却有力地融入专业学习的典 范, 达到育心无形的效果。

\section{案例二: 共价键的本质(发展观、终身学习观)}

化学键理论是结构化学课程核心内容之一, 现代化学有关共价键本质有两个主流理论: 价键理 论和分子轨道理论, 其发展过程是从此消彼长到齐头并进的过程, 这一发展过程符合马克思主义哲 学的认知论和实践论。量子力学理论一经建立, 化学家运用量子力学理论研究分子的化学键, 推进 了现代化学键理论体系的建立。1927年6月海特勒和伦敦发表了一篇经典性的论文, 成功地运用量子 力学讨论了氢分子 $\mathrm{H}_{2}$ 的核-电子相互作用体系, 初步解释了化学键共价键的本质, 标志着价键理论的 诞生。斯莱特和鲍林等人加以发展, 特别是鲍林等人提出的共振论和杂化轨道理论, 为价键理论的 发展做出了很大贡献。由于价键理论与经典的化学键概念相吻合, 从一开始就得到了迅速发展, 并 开始占据统治地位。但价键理论无法完美解释共轭分子结构等, 同时由于价键理论具体计算上的困难 (基函数难以计算机化), 使此方法一度停滞不前。于是, 分子轨道理论逐步引起人们的重视。1928年, 马利肯和洪特提出分子轨道理论, 后经休克尔、福井谦一、伍德沃德和霍夫曼等加以发展, 形成一 套成熟的理论。分子轨道理论是把分子看成一个整体, 分子中的电子围绕整个分子运动, 体现了一 种整体论的思想, 能解释当时价键理论无法解释的现象, 如 $\mathrm{O}_{2}$ 分子的顺磁性, 并成功解释分子光谱 实验数据。同时, 分子轨道理论在数学上易于计算, 结果可定量, 特别是应用分子轨道理论可预测 化学反应的可行性, 使得分子轨道理论得到空前的发展。20世纪50年代开始, 分子轨道理论逐步代 替价键理论, 占据了主导地位。不可否认的是, 价键理论对分子静态性质如结构、成键特征及动态 性质如键的形成与断裂的描述, 有分子轨道理论无可比拟的优越性。后来, 价键理论也发展了一些 新的计算方法, 如我国厦门大学张乾二院士及其团队在此方面做了很多创新性研究工作。目前, 量 子化学中两大主流理论齐头并进地发展, 从不同的角度 (定域与离域, 整体与局部)解释实验数据与 事实, 预测实验结果。化学键理论能否取得完美的统一, 是化学家正在致力于解决的问题。通过介 绍化学键电子结构理论的发展脉络及优缺点, 引导学生认识到理论与实验事实的矛盾是科学发展源 源不断的动力, 培养学生思辨能力、科学的发展观和终身学习观。

\section{案例三: 量子力学理论的解释(实践论)}

量子力学是 21 世纪物理学极为重大、极为基础的理论, 是人类探究微观世界的重大成果。量子 力学建立在一些公理的基础上, 这些基本假设不能直接证明, 只能通过应用量子力学理论直接解释 实验事实, 以及利用其理论发展新的实验技术来证实量子力学是牢靠的认知微观世界的基础理论。 目前为止量子力学通过了所有的实验检验, 无一败绩。20世纪的很多重大科技发明, 如核能、半导 体器件、激光等都是在量子力学的指导下成为现实的。2013年, 量子力学 “标准模型” 所预言的最 后一个基本粒子——希格斯玻色子被实验发现, 当初预言该粒子存在的比利时物理学家弗朗索瓦. 恩 格勒和英国物理学家彼得. 希格斯也顺理成章地获得了2013年诺贝尔物理学奖。通过以量子力学为指 导的科学研究应用介绍, 使学生认识到: 实践是检验真理的唯一标准, 脱离实践的检验, 认识论容 易陷入机械论, 甚至唯心论。将深奥的不可见的微观理论与可触摸的科学仪器以及科学家的发现活 动关联起来, 促进学生基础理论知识的学习兴趣, 使思政元素促进专业要素的学习, 实现思政与专 业的互动互融。在具体的科学事例中, 介绍我国在量子科技领域突破的一系列重要科学问题和关键 核心技术,产出的多光子纠缠干涉度量、量子反常霍尔效应、世界首颗量子科学实验卫星 “墨子号”、 量子保密通信 “京沪干线” 、世界首台光量子计算原型机等一批具有重要国际影响力的成果, 可提 高学生的文化自信, 增强民族自豪感和使命感, 激发学生学习热情。 


\section{2 从结构化学教学方法出发挖掘思政元素}

结构化学是研究物质的微观结构与其宏观性能关系的基础科学。物质的微观结构是基于量子力 学理论的预测, 现代测试技术的发展为物质的结构与性质测试提供实验数据, 进行结构测定的目的 在于掌握性能与结构之间的联系，从而找出其内在规律。各种分析测试手段都有其各自的局限性， 因此在进行结构分析时总是应用各种探针施之于物质，从中得到各种信息，再把这些信息综合起来， 通过去伪存真、去粗取精、由此及彼、由表及里的连贯思索, 最后再做出判断。了解新的思维方式, 建立创新思维观念, 并鼓励学生运用创新思维去解决问题。

\section{案例四：双原子分子结构(创新思维)}

在双原子分子结构与性质教学过程中, 采用案例教学法, 认识分子结构与化合物性质之间的联 系, 从而理解掌握 “结构决定性质” 这一原则。例如, 应用分子轨道理论可知, $\mathrm{N}_{2}$ 分子的电子组态 为 $1 \sigma_{\mathrm{g}}^{2} 1 \sigma_{\mathrm{u}}^{2} 2 \sigma_{\mathrm{g}}^{2} 2 \sigma_{\mathrm{u}}^{2} 1 \pi_{\mathrm{u}}^{4} 3 \sigma_{\mathrm{g}}^{2}$, 其键级为 3 , 因而 $\mathrm{N}_{2}$ 化学稳定性较好, 是惰性较大的分子。根据热力学数据 进行计算可得, 合成氨反应 $\left(\mathrm{N}_{2}(\mathrm{~g})+3 \mathrm{H}_{2}(\mathrm{~g})=2 \mathrm{NH}_{3}(\mathrm{~g})\right)$ 是一个自发反应过程, 然而人工合成氨需要苛 刻的条件才能进行。正是因为人工合成氨的重要意义及其苛刻的反应条件造就了与工业合成氨工艺

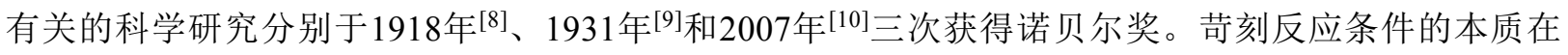
于 $\mathrm{N}_{2}$ 中化学键极其稳定, $\mathrm{N}_{2}$ 活化的普遍共识是: 金属原子与 $\mathrm{N}_{2}$ 形成配合物, $\mathrm{N}_{2}$ 最高占据轨道(成键分 子轨道)电子进入金属原子空的杂化轨道形成 $\sigma$ 型配位键, 同时金属原子的 $d$ 电子进入到 $\mathrm{N}_{2}$ 分子最低空 轨道(反键分子轨道)形成 $\pi$ 型反馈配位键, 从而削弱了 $\mathrm{N}_{2}$ 分子三键。这一普遍共识正是从 $\mathrm{N}_{2}$ 的电子组 态出发, 找出活化 $\mathrm{N}_{2}$ 的结构因素, 采用综合分析法, 考虑所有可能的反应途径, 对比分析, 得到最 优合成路线。这种从结构的阐明(从分析到综合)到指导合成甚至是设计合成路线(从综合到分析), 再 从合成实验的探索, 反馈到结构的确证, 最后达到完全自洽的认知。整个过程就体现了科学的思维 过程。这样思政要素融入的教学设计, 不仅使学生学习基本理论知识, 同时全面系统地掌握如何从 研究问题到提出新理论、新成果的完整的、科学的、创新的思维方法, 实现了专业知识学习、能力 培养的互动共赢。

\section{案例五: 微观粒子的波粒二象性(类比法、创新能力)}

在科学史上, 对光的本质的认识存在长达数个世纪的激烈争论。从 17 世纪起, 光的本质就有牛 顿的微粒学说, 以及惠更斯的波动学说, 因为波动学说的缺陷及牛顿的声望, 粒子学说一度占了上 风。1801年托马斯·杨的光的双缝干涉实验支持了波动学说, 在随后的几十年里又出现了更多的证据, 如: 光的衍射实验, 赫兹验证了麦克斯韦的光是电磁波的预言, 光的波动学说取得压倒性的胜利, 最终微粒学说被所有人抛弃, 直到19世纪末物理学家深信光是波而不是粒子。20世纪初, 人们又发 现了新的实验证据支持光是粒子, 直到1905年爱因斯坦受普朗克的能量子观点的启发, 提出光子学 说, 发展了牛顿的光的微粒学说, 成功解释了光电效应。自此光具有波粒二象性, 被物理学家所认 可。爱因斯坦说过: “我们面对着新的一类困难。我们有两个矛盾的现实图像, 两者之一都不能单 独完全解释光现象, 但二者一起可以。”此后, 德布罗意受光的波粒二象性的启发对微观粒子提出 实物粒子具有波粒二象性, 这是科学史上应用类比法的典范。面对微观粒子了解他们的唯一工具只 有实验, 电子衍射实验证实电子具有波动性。微观粒子的粒子性和波动性对立统一, 相互依存又相 互排斥, 在不同的研究中, 微观粒子有时表现出粒子性, 有时表现出波动性, 这正是由主要矛盾的 主要方面决定的。通过这段科学史实, 引导学生体会人的认识过程是辩证发展的过程, 大胆猜测, 小心求证, 且从想象发展到科学, 主要是依据科学实验; 培养学生发展的全局观、实事求是的科学 精神和创新精神。同时, 每位科学家的治学之道、献身精神本身就是培养学生坚定意志品质和奋发 不屈精神的教材, 引导学生学习和践行坚持求真、勇于创新等正确的人生价值观。

\section{3 从理论化学家故事出发挖掘思政元素}

创造知识过程的关键是 “人”, 科学家的人性光辉比他们取得的科学成就更能打动学生的心灵。 从中国科学家故事出发, 将冷冰冰的知识和鲜活的科学家结合起来, 引出国家意识、树立爱国情怀、 
体会创造知识过程的艰辛、歌颂自强不息的精神。 的故事

案例六: 在化学键理论教学中, 介绍科学家徐光宪先生发展我国化学教育, 提高科学研究水平

徐光宪(1920-2015), 理论化学家, 中国科学院院士。获国家最高科学技术奖, 编写《物质结构》 教材获国家优秀教材特等奖, 建立了适用于研究稀土元素的量子化学计算方法和无机共轭分子的化 学键理论。在 20 世纪朝鲜战争爆发之际, 徐光宪先生毅然放弃在美国即将到手的工作, 于1951年4月 与夫人高小霞一起回到祖国, 在北京大学化学系从事量子化学和络合物化学方面的研究。从1972年 开始, 徐光宪先生围绕国家战略需要转向稀土分离和萃取方面的研究, 并很快获得突破, 提出了适 于稀土溶剂萃取分离的串级萃取理论, 引导稀土分离技术的全面革新, 促进了中国从稀土资源大国 向高纯稀土生产大国的飞跃。通过徐光宪先生的人格魅力和科学精神, 鼓励学生勤奋务实、刻苦钻 研、勇于探索、不断创新, 为祖国的繁荣和强大而努力学习。这同时又是培养学生家国情怀、责任 担当的极好伟人故事, 激发他们的学习热情和责任意识。

\section{案例七: 在理论化学发展史中, 介绍科学家唐敖庆发展我国理论化学学科的故事}

20 世纪70年代, 我国理论化学学科面临后继无人的严峻局面, 在唐敖庆先生的倡议下, 吉林大 学理论化学研究所在1978-1980年举办为期三个学期的全国量子化学进修班。这期进修班集理论化学 精英之力, 为研究生讲授一年半的基础理论课程, 在今天可能被认为痴人说梦。唐敖庆先生在这期进 修班的总结时, 对学员如是说: “从事理论化学研究就像登喜马拉雅山, 进修班把你们送到了8000米 的高度, 剩下的 800 多米就要靠你们自己攀登了。”也正是这期进修班为我国理论化学学科的发展做 出了历史性的贡献。徐光宪先生在《继承唐敖庆先生遗志, 展现当代中国化学风采》文集的 “代序” 中指出： “如果没有唐先生和卢先生倡导的 “四结合” (微观与宏观结合、理论与实验结合、静态与 动态结合、结构与性能结合)教学和科研指导思想, 那么我们国家大学本科的教育水平, 将落后国际 水平30年。” 通过唐敖庆先生的教育情怀, 鼓励学生投身我国基础教育事业, 志存高远, 乐于奉献, 勇于担当, 为实现教育理想, 不断努力提升教师专业素质。

以上仅列举了结构化学课程重构中挖掘思政元素几个个别案例, 客观分析结构化学课程各章节 教学内容的特色, 不缺少思政元素融入课堂教学的案例和方法。课程教人求 “真”, 也可以教人求 “美”, 结构化学课程中不乏 “美” 的元素, 例如, 量子力学基本假设及点阵理论的逻辑严谨之美、 不确定关系及薛定谔方程的简洁之美、分子结构及自组装图案的对称之美，等等。

\section{4 结构化学课程思政教学效果}

本课程团队一直注重结构化学教学改革与实践, 取得了一定成效, 曾获批省级精品课程、省级 资源共享课程, 教学改革成果作为主要内容获得国家级物理化学教学成果二等奖。这些成绩的取得 部分得益于结构化学课程教学中融入思政元素、采用案例教学法等改革措施。通过课下与学生交流, 了解到这些措施的实施使学生在一定程度上克服了学习结构化学的畏难情绪, 转变了学习态度, 激 发了学习兴趣, 提高了学习能力和学习成绩。学生反映, 以前主要关注知识本身, 现在会同时思考 他人是怎么做的, 我为什么要这么做; 开始关注科学原理中的哲学意义, 发现了思考的快乐, 树立 了学习的信心。同时, 对课程考核方式进行丰富和提升, 采取了注重学习过程的多维度测评方式, 综合评价学生的学习过程, 培养学生持续稳定的学习能力。主要考核方式由课程小论文、课堂交流 讨论、章节作业与测试和期末考试等环节组成。章节作业与测试考试主要考查学生对课程理论基础 知识及其应用的掌握程度, 课程小论文与课堂交流讨论等则注重学生课程学习参与度、思辨能力、 语言表达能力、分析归纳总结能力考查, 引导学生通过深入思考, 提升自身的学术能力。多维度的 考核形式能更加客观地反映学生的学习情况。章节作业抄袭现象明显减少, 且在解答类作业中尝试 新思路、新解法的情况增多, 质疑习题参考答案正确性的同学也有所增多, 且有不少同学能给出正 确合理的判断, 科学作风更加严谨, 课程不通过率明显下降, 优秀率有所提升。就课程教学效果对 
学生职业发展的影响来看, 在毕业生升学方面, 近年来非师范专业报考理论与计算化学方向研究生 人数显著增多, 且多人被厦门大学、吉林大学、西安交通大学、北京师范大学等高校录取。从师范 专业毕业生反馈得知, 承担高中化学选修三(结构与物性)教学任务得心应手。

\section{5 结语}

课程是高等学校培养人才的知识载体, 对专业课程进行思政元素重构正成为教学改革的重要方 法, 在潜移默化中实现教育目标, 切入点十分重要。本文以结构化学课程为例, 通过挖掘和提炼该 课程中所蕴含的思政元素和承载的德育功能, 将知识传授和价值引领相结合, 将育人工作落实于课 堂教学的主渠道中。结构化学课程思政教学元素的重构和实施仍然需要有完善的空间, 比如优化思 政元素、调整思政内容占比、摸索更好的课程思政教学模式、建立更优的教学效果评价体系。在结 构化学课程教学中融入思政教育, 既丰富了课程教学内容, 增加了教学多元性, 又有助于学生掌握 结构化学的基本理论和知识的同时, 增强学生的创新意识和创新思维, 促进学生哲学观、科学观的 形成, 达到立德树人的目的。通过课程思政元素的挖掘, 也提高了教师课程思政的意识和能力, 实 现了教师的自我发展。

\section{参 考 文 献}

[1] 习近平在全国高校思想政治工作会议上强调: 把思想政治工作贯穿教育教学全过程开创我国高等教育事业发展新局面. 人民日报, 2016-12-09 (1).

[2] 张树永. 大学化学, 2019, 34 (11), 4 .

[3] 王旭珍, 王新平, 王新葵, 田福平, 田东旭, 陈冰冰. 大学化学, 2019, 34 (11), 77.

[4] 郭玉鹏, 王瑞, 李艳梅. 中国大学教学, 2019, No. 9, 65 .

[5] 徐玲, 魏恒伟, 魏灵灵, 马艺, 王晓明, 焦桓. 大学化学, 2021, 36 (3), 1912042.

[6] 周公度, 段连运. 结构化学. 北京: 北京大学出版社, 2017.

[7] 孙宏伟. 结构化学. 北京: 高等教育出版社, 2016.

[8] The Nobel Prize in Chemistry 1918. NobelPrize.org. Nobel Media AB 2021. [2021-01-06]. https://www.nobelprize.org/prizes/chemistry/1918/summary/

[9] Carl Bosch-Facts. NobelPrize.org. Nobel Media AB 2021. [2021-01-06]. https://www.nobelprize.org/prizes/chemistry/1931/bosch/facts/

[10] Advanced information. NobelPrize.org. Nobel Media AB 2021. [2021-01-07].

https://www.nobelprize.org/prizes/chemistry/2007/advanced-information/ 